\title{
Structural Retrofitting of Old Illyria Hotel
}

\author{
Feti Selmani $^{1}$ and Musa Stavileci ${ }^{2}$ \\ 1. PAN Engineering, Sofali 10000, Kosovo \\ 2. Faculty of Civil Engineering and Architecture, University Hasan Prishtina, Sofali 1000, Kosovo
}

\begin{abstract}
Illyria hotel (formerly Bozhur) was built during the sixties in the heart of the actual Kosovo's capital Prishtina, according to former old Yugoslav standards in a Modernist architectural style. It represents a massive structural system with brick walls up to $54 \mathrm{~cm}$ thick and "avramenko" type reinforced concrete floors. The investor's aim was to add another two floors on the top of the existing ones and to build two level underground parking floors, a health spa centre, whilst at the vicinity of the existing building (the northern side) to erect a new 17 story-high brand new hotel and administration building. The retrofitting of the structure as well as construction of the new structure has been done in full accordance with the new structural Eurocodes' recommendations. 3D FEM (finite element method) modeling was used for the analysis and design, using ETABS v 9.5 nonlinear and ARSAP 2010 (Autodesk Robot Structural Analysis Professional 2010). Response spectrum design according to $E C$ 8,3.2.2.4 has been used for seismic analysis and design with a reference peak ground acceleration on type A ground of $A_{g R}=0.25 \mathrm{~g}$.
\end{abstract}

Key words: Structural retrofitting, reinforced concrete shear walls, foundation strengthening, column jacketing.

\section{Introduction}

The old Illyria hotel (formerly "Bozhur") is a landmark building situated in the very centre of Kosovo’s capital Prishtina (Fig. 1), designed according to the modernist architectural style. The building was designed and built during the late sixties according to the old Yugoslav-JUS standards, and consisted of two underground floors, a ground floor and another five floors above. The architectural design represents a set of four (4) building blocks: blocks A and B (the old hotel), block $\mathrm{C}$ (the new hotel and administrative building) and block D (the underground parking lot, a spa centre and a conference hall on the first floor). The owner's wish was the erection of yet two other floors on top of the existing ones (blocks A and B). This task was the most challenging one, since the old structure had already been in a poor state. After having thoroughly examined different possibilities, three possible solutions arose, namely:

(1) the demolition of the old building and the

Corresponding author: Feti Selmani, M.Sc., research fields: structural engineering, passive control and bio-structures. E-mail: panengineering@gmail.com. erection of a new one;

(2) structural retrofitting of the existing structure and the erection of the two stories on top of the existing ones.

The second possibility was chosen in discussions with the owner and the architect. In these circumstances, three possibilities were analyzed:

(1) retrofitting of the old structure with CFRP (carbon fibres-reinforced polymers);

(2) steel "X" bracings;

(3) conventional structural elements' jacketing.

The later approach was chosen mainly because of economic as well as knowledge reasons, since reinforced concrete is a well known material here in Kosovo, whereas the two first possibilities require an extended schedule and a different level knowledge.

The challenge was to find an original solution to the problem by designing a completely new reinforced concrete structure extending from under the existing foundations to the top of the newly added floors (level + $25.89 \mathrm{~m}$ ). Having into consideration the poor physical state and mechanical characteristics of the existing concrete (MB 15.20) as well as clay blocks 


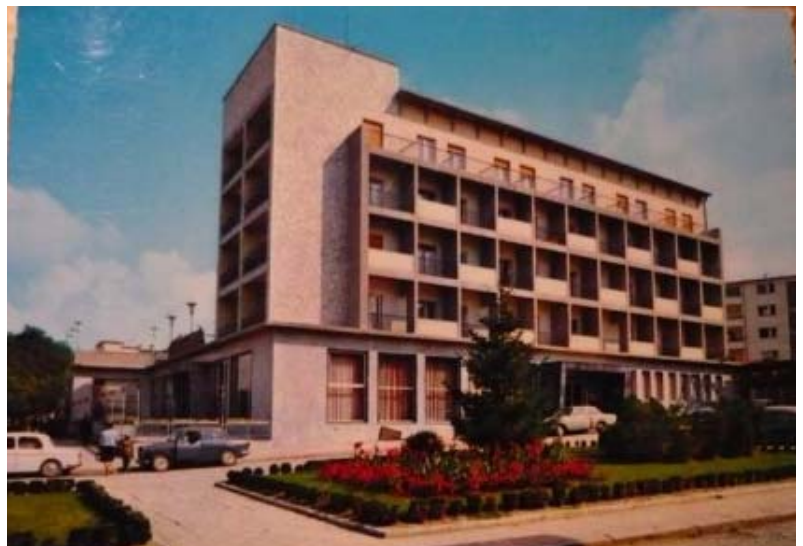

Fig. 1 The old Illyria hotel (formerly hotel Bozhur) - photo taken around seventies-a modernist style icon in the heart of Kosovo's capital Prishtina.

and clayed bricks, the newly erected structure had been analyzed and built fully independent (except the foundations) from the existing one and serves exclusively to support (both vertically and laterally) the two new top floors. Laterally, the structure is stabilized through new shear walls which run in two "principal" directions and only a monolithic connection with the middle row of the existing columns situated on the fifth floor below has been made.

\section{Geotechnical Conditions}

After careful examinations of the site, seven boreholes have been drilled: three at the southern side and four at the northern side of the future building blocks, whereas seven points with static penetration and two points with geophysical-geological measurement have also been taken in order to fully assess the underground soil conditions for the construction site [1]. The first four meters (borehole B2) consisted of silt and sandy clay with medium to high plasticity (in hard to very hard consistency) of brown color (Fig. 2a), whilst at a depth of approximately $8 \mathrm{~m}$ (the level of the underground water table) a mixture of well-granulated gravel and sand was detected [2]. A 60 $\mathrm{cm}$ thick foundation slab has been designed for the block D (wellness centre-see Fig. 3) at this level (SL_001, axes A'-L/8'-5). A soldier bored pile wall with a pile diameter of $\phi 600 \mathrm{~mm}$, distant $1,200 \mathrm{~mm}$

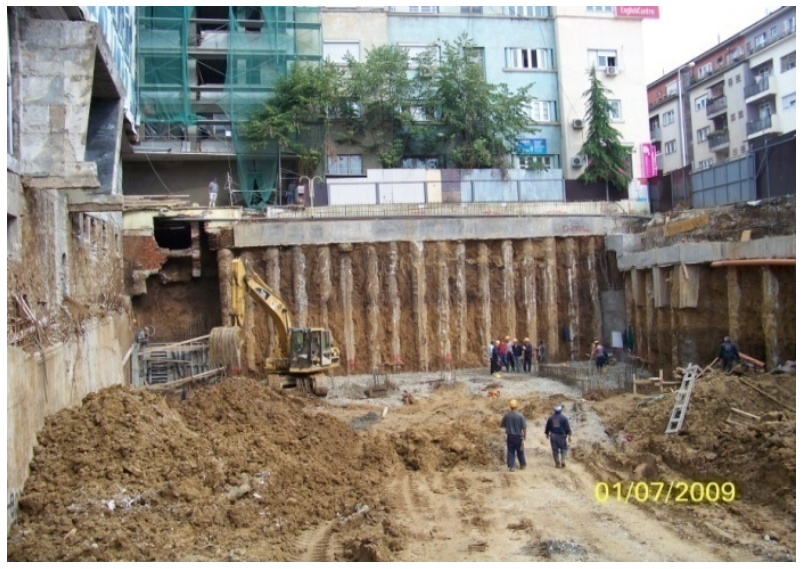

(a)

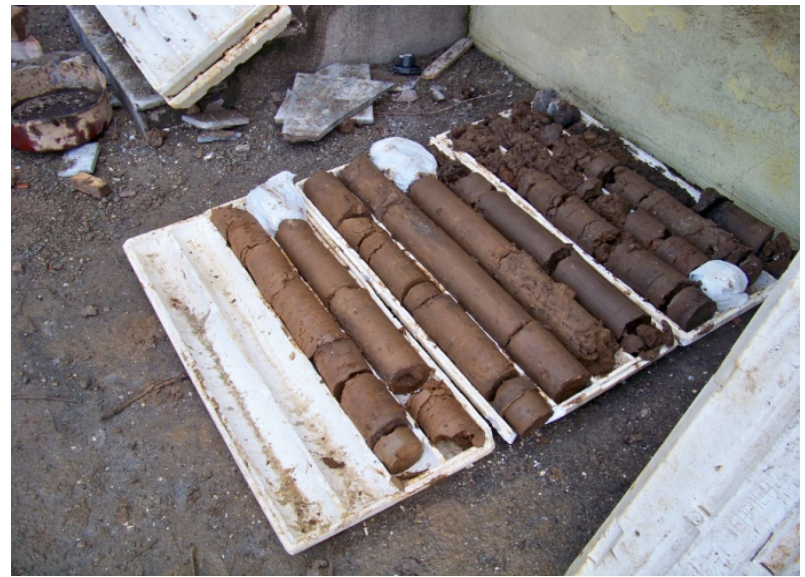

(b)

Fig. 2 (a) photo showing the soil samples; (b) soldier bored pile wall with a pile diameter of $\phi 600 \mathrm{~mm}$ for the purpose of the ground support provision.

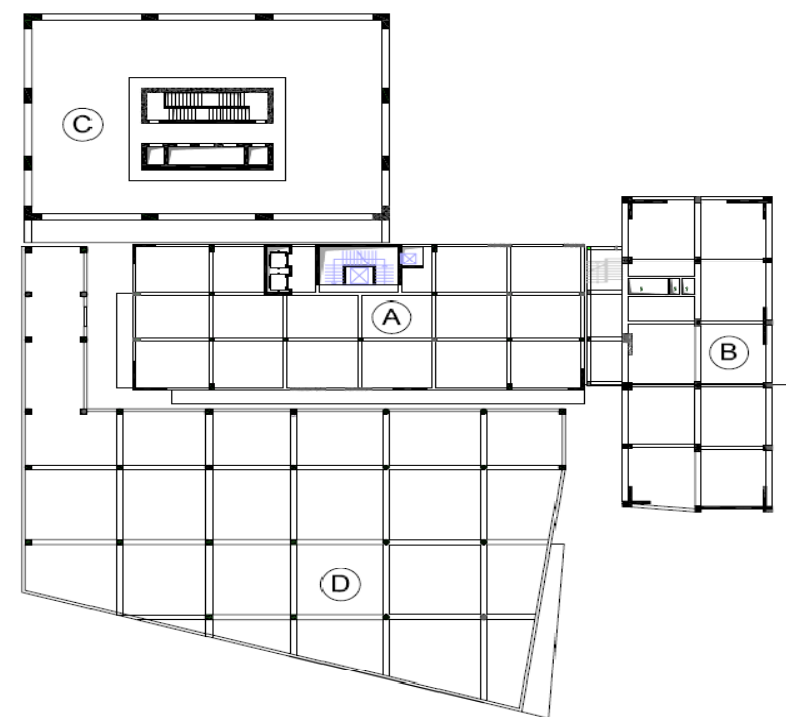

Fig. 3 Layout of Illyria complex building blocks: A and $\mathrm{B}$ - existing building (old hotel); $\mathrm{C}$ - the new 17-stories hotel and $\mathrm{D}$ - the spa centre. 
axially [3], was used for the provision of the ground support on permanent basis (Fig. 2b).

The bearing capacity of the soil is given as a function of the borehole's position, and varies from $250 \div 300$ $\mathrm{kPa}$ with a safety coefficient of 3 [1]. A subgrade modulus $\left(k_{z}=\sigma_{0} / s\right)$ of $k_{z}=10,000 \div 20,000 \mathrm{kN} / \mathrm{m}^{3}$ had been taken for analysis purposes. Thus, for analysis and design of block $\mathrm{C}$ (the new 17 storey hotel) a $k_{z}=$ $10,000 \mathrm{kN} / \mathrm{m}^{3}$ value of the sub-grade modulus was considered, whereas the soil stress resulting from the analysis is $\sigma_{\text {soil }}=382 \mathrm{kN} / \mathrm{m}^{3}$. A layer of well granulated and well compacted gravel $80 \mathrm{~cm}$ thick (in layers of no more than approximately $20 \mathrm{~cm}$ thick) had been laid under the foundation slab prior to the laying of reinforcement and concrete.

\section{Structural Analysis and Design}

Structurally, Illyria complex is composed of four independent dynamic units: block A and B (old hotel), $\mathrm{C}$ (new hotel and administrative building) and D (spa centre) as shown in Fig. 4.

\subsection{Materials}

Neither reinforcing details nor other drawings could be found after the first author has searched in the city's archives. Samples of existing reinforced concrete were taken at various places on the existing structural elements and after the examinations a mean value of C16/20 concrete class could be established at the best possible case.

A C25/30 (EC2-1-1, cl. 3.1) concrete class was adopted for all reinforced concrete structural elements, such as beams and structural slabs, whereas a C30/37 concrete class was adopted for shear walls as well as the vertical elements such as reinforced concrete structural columns (columns jacketing also) for building blocks A, B, C and D. Reinforcing steel of high ductility class B500B (EC2-1-1, cl. 3.2) had been used for analysis and design [4].

Structural slabs for block $\mathrm{C}$ are made of reinforced concrete, $25 \mathrm{~cm}$ thick (in accordance with EC 2,4.1.3 and EC 2,7.4.2, Table 7.4N), whilst for the blocks A and $\mathrm{B}-\mathrm{A}$ prefabricated solution was adopted, consisting of a $6 \mathrm{~cm}$ layer of concrete poured in situ on the top of lightweight and fast forming system with EPS (extruded polystyrene) filling prefabricated panels. The main reason for choosing this system was to contain structural dynamic mass as low as possible. The partial factors for materials have been considered from the respective parts of EC 1992 to EC 1998.

\subsection{Actions}

All actions for analysis and design were considered in full accordance with the requirements of EC1 1991-1-1 to EC1 1991-1-7, while the combinations of actions were considered according to EC 1990, cl. 6.4.3.2 $\div$ 6.4.3.4 for various design situations [5].

The imposed loads were taken into account in accordance with Table 6.1 of EC1 1991, whilst the $\psi$ values are taken from Table A.1.1 of EC 1990 [6].

Seismic action was considered in accordance with the requirements of (EC 1998, cl. 3.2.1) with a recommended value (from the part of a geotechnical expert) of the reference peak ground acceleration on ground type A $a_{g R}=0.3 \cdot \mathrm{g}$, where $g=9.81 \mathrm{~m} / \mathrm{s}^{2}$. Thus, the design value of ground acceleration on type $\mathrm{A}$ ground results as $a=r_{1} \cdot a_{g R}=1.2 \cdot 0.3 \cdot \mathrm{g}$, where: $r_{l}$ is the importance factor and according to EC 1998, cl. 4.2.5, Table 4.3, importance class II has been assumed, therefore the recommended value of $r_{1}=1.20$. The behavior factor $q=3.5$ was taken, as the structure was designed as a DCM (ductility class medium) structure in accordance with the recommendations of EC 1998, cl. 5.4 [7]. The horizontal components of seismic action are introduced as of Type 1 according to EC 1998, cl. 3.2.2.5, eq. 3.12 to 3.15 for a ground type B (in accordance with the geotechnical report), whereas the vertical component of the seismic action had not been considered (see EC 1998, cl. 4.3.3.5.2).

The inertial effects of the seismic action were considered as per expression (3.16 of EC 1998, cl. 3.2.4), whilst the combination of actions is in 
compliance with EC 1998, cl. 4.3.3.5 (2), that is by the SSRS (square root of the sum of squares) of the action effect due to each horizontal component ( $E_{E_{d x}}$ respectively $\left.E_{E_{d y}}\right)$.

\subsection{Analysis and Design}

State-of-the-art software ETABS nl v.9 and ARSAP 2010, were used for analysis and design of the structure. Results, such as periods of vibration, frequencies or displacements were confronted with each other and as an outcome there were satisfactory results. A 3D FEM (finite element method) mathematical model of the structure was considered, with its six degrees of freedom per node (three displacements plus three rotational DOF's). Structural slabs for the two new stories (level $+17.19 \div 25.89 \mathrm{~m}$ ) on top of the existing structure (blocks A and B) are of "lightweight and fast forming system for concrete floors" type, with EPS supplemented with additional rebar in-between, in order to increase the deck resistance. The reason for the selection of the above-mentioned system was based mainly on the fact of decreasing the structural mass, as the floor is situated at a considerable height $(+20.79 \mathrm{~m}$, SL_700a) above the foundation's level (foundation level is at $-4.06 \mathrm{~m}$, see Fig. 5).

For dynamic analysis purpose, structural concrete slabs are modeled as rigid diaphragms with only three degrees of freedom per story (two horizontal displacement degrees of freedom and a rotational degree of freedom). The reason for this was the downsizing of the enormous amount of calculations needed as well as to increase the speed of decision-taking relatively to the stiffness deployment, on a local or on a global extent of the structure. In addition, for the purpose of comparison of the obtained results, what had been considered is a $3 \mathrm{D}$ mathematical model of the structure (for all building blocks A, B, C). Fig. 5 shows the first three mode shapes of the structure of building block $\mathrm{C}$, where one can see clearly the distinction between the two first periods of motion (translations) and the third one (torsion). This is an indication [7] of the structural regularity according to EC8, cl. 4.2.3.2 (although not directly stated by it).

\section{Construction and Detailing}

As the structure was designed of a medium ductility (DCM), special attention was paid to the detailing of reinforcement for columns, beams and the shear walls (Fig. 6) [7].

According to calculations for the old building, approximately $20 \%$ of the foundations bearing capacity would have been exceeded by adding another two floors on top of the existing ones, therefore, a strengthening became necessary. In Fig. 7, one can see a typical detail of foundation strengthening as well as column jacketing through lattice metal structure (the basement level).

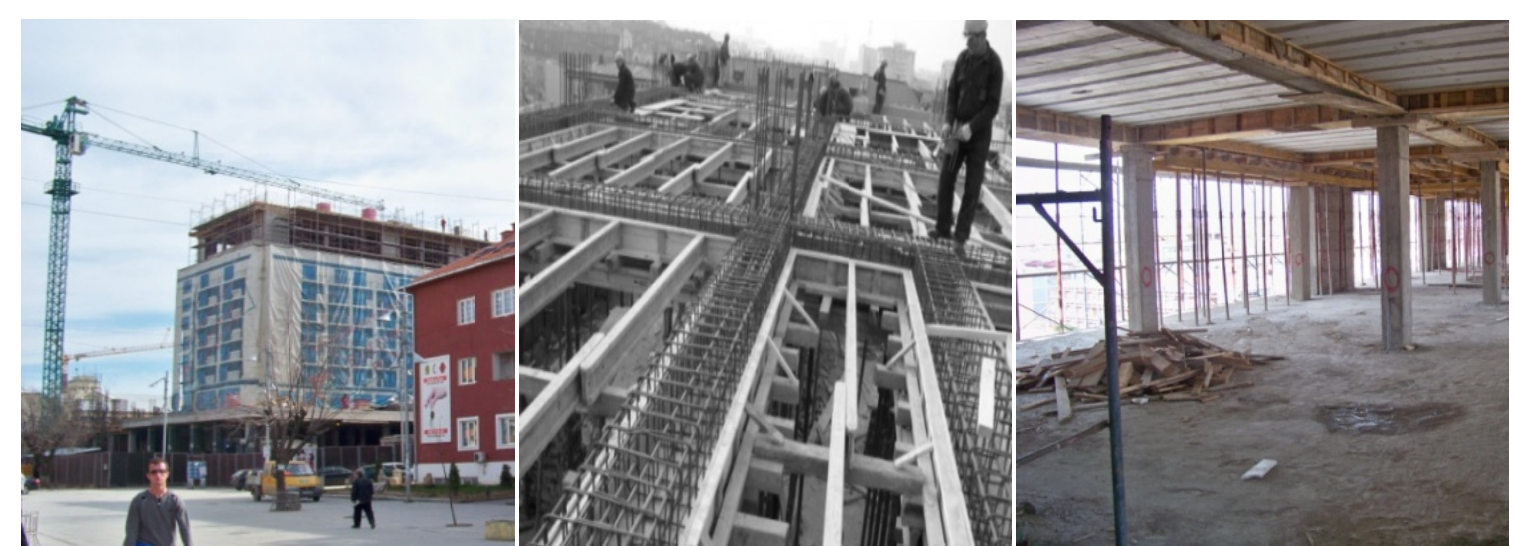

Fig. 4 Layout of Illyria complex building blocks: A and B-existing building (old hotel); C-the new 17-stories hotel and D- the spa centre. 

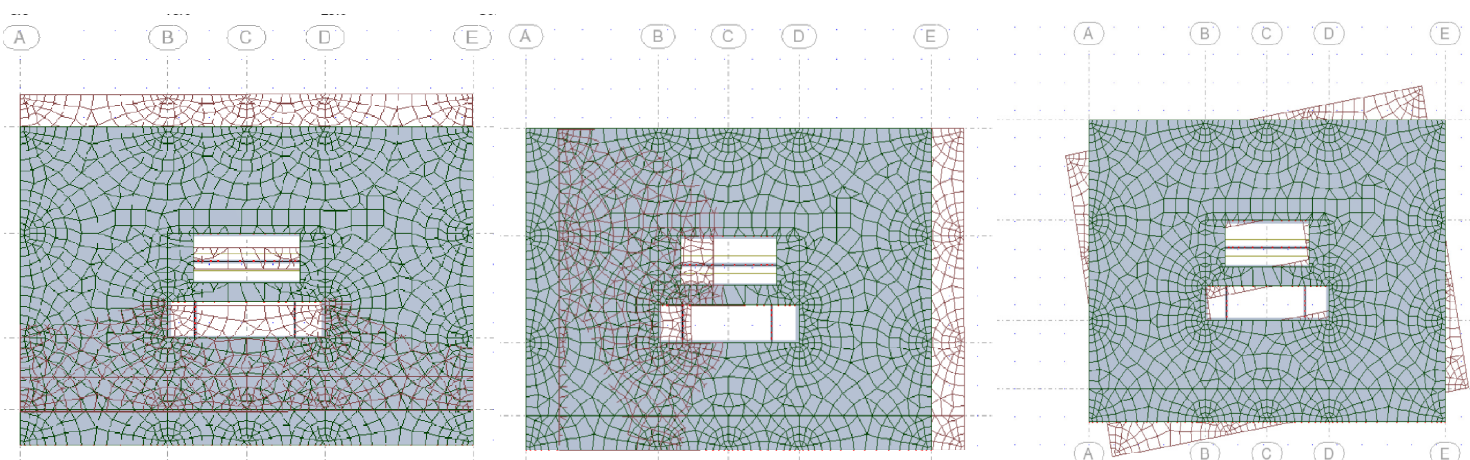

Fig. 5 Layouts of the 3D mathematical model-building block $C$; the first three mode shapes of vibration: $T_{1 \text { transl }}=1.82 \mathrm{~s}$, $T_{2 \text { transl }}=1.51 \mathrm{~s}, T_{3 t o r s i n}=0.75 \mathrm{~s}($ ARSAP 2010).

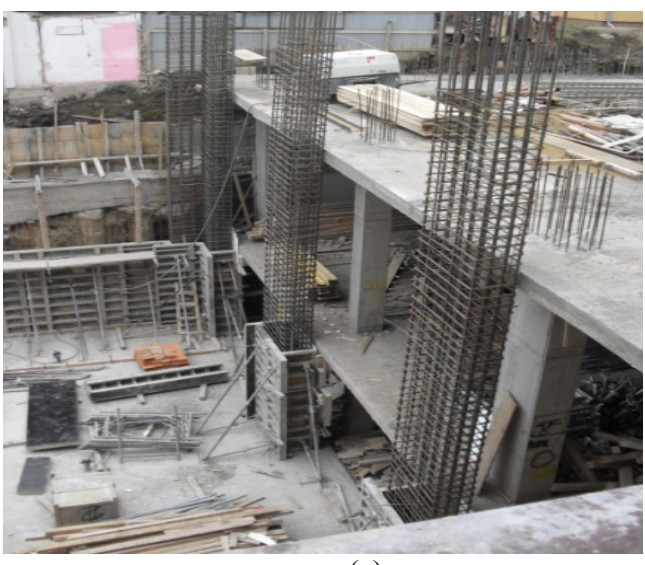

(a)

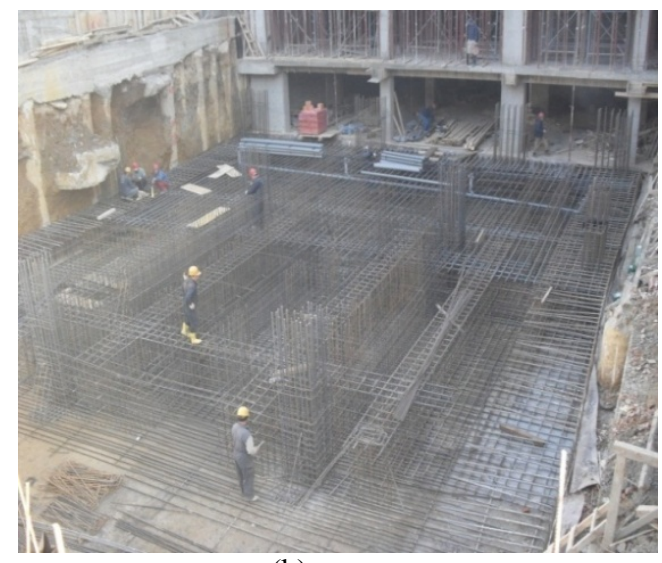

(b)

Fig. 6 (a) The structural columns' reinforcement for the critical regions (EC 1998, CL.5.4.3.2); (b) reinforcement for the foundation slab-building block $\mathrm{C}$.

(a) Formworks

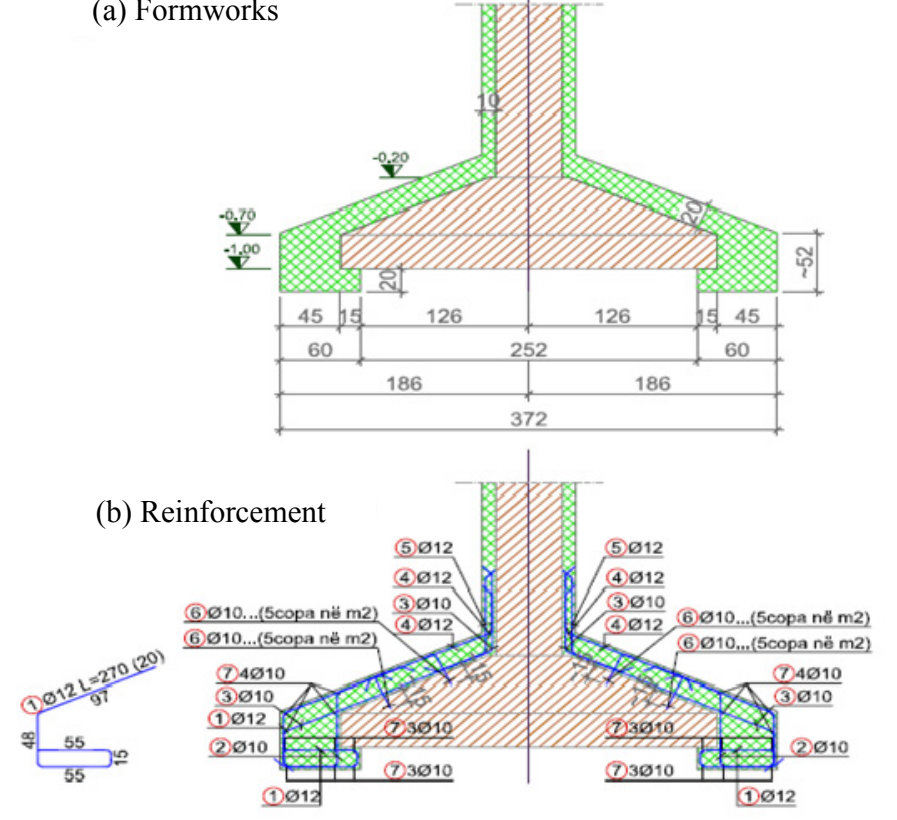

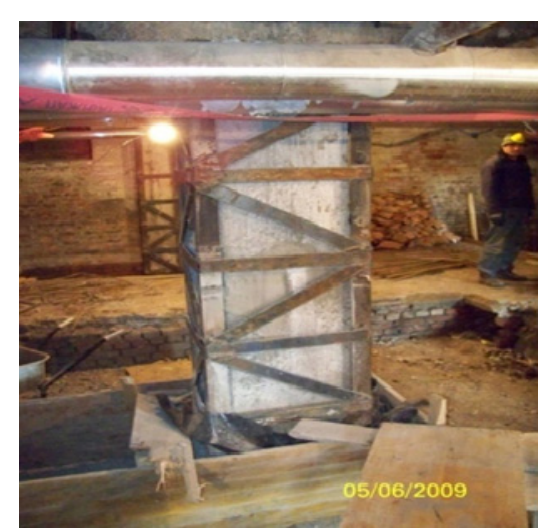

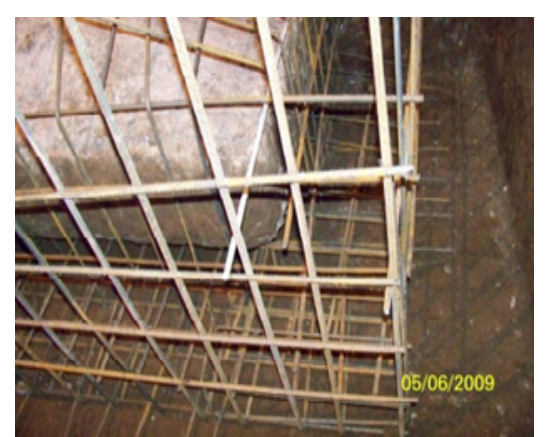

Fig. 7 Left: column jacketing (at the basement level—block A); Right: foundation strengthening. 


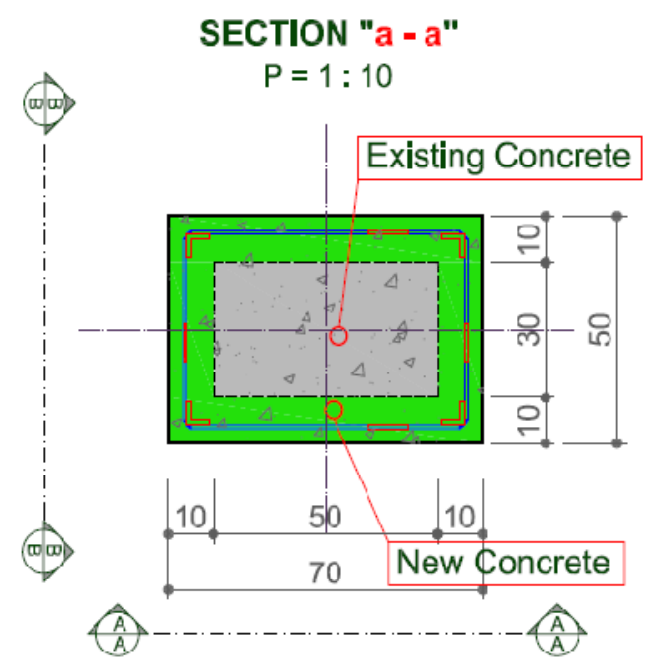

(a)

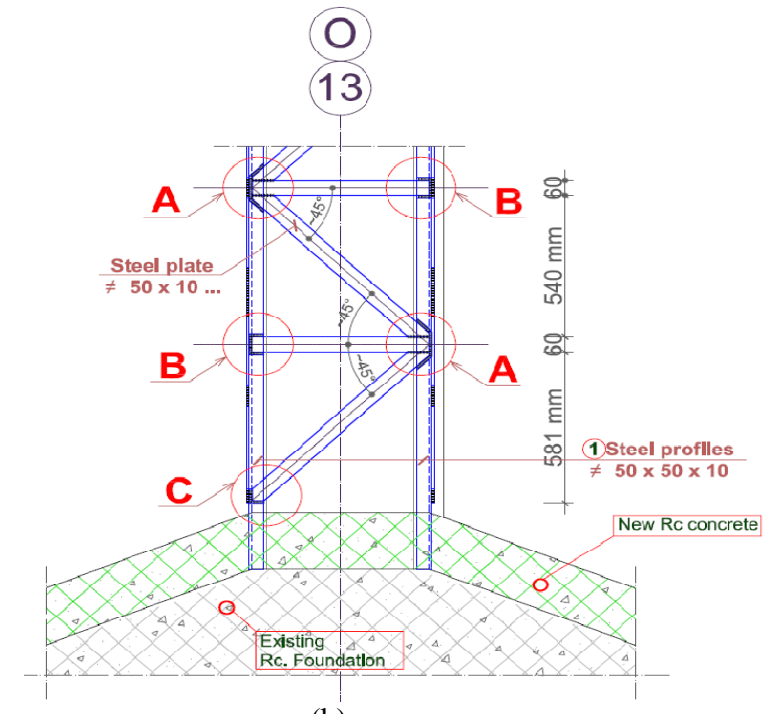

(b)

Fig. 8 The existing reinforced concrete columns: (a) column jacketing (at the basement level—block A); (b) foundation strengthening.

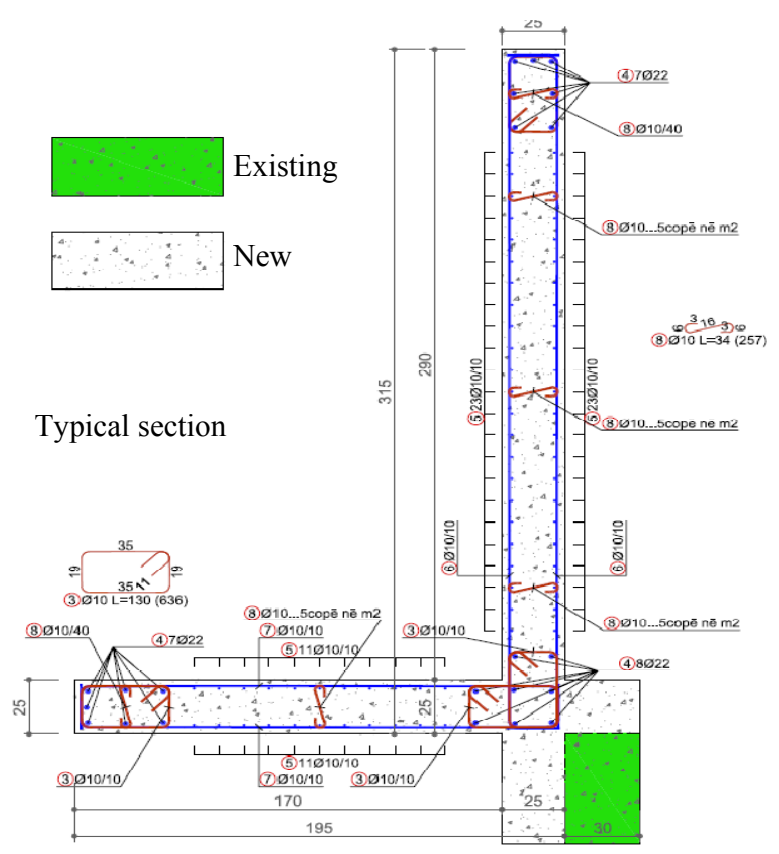

(a)

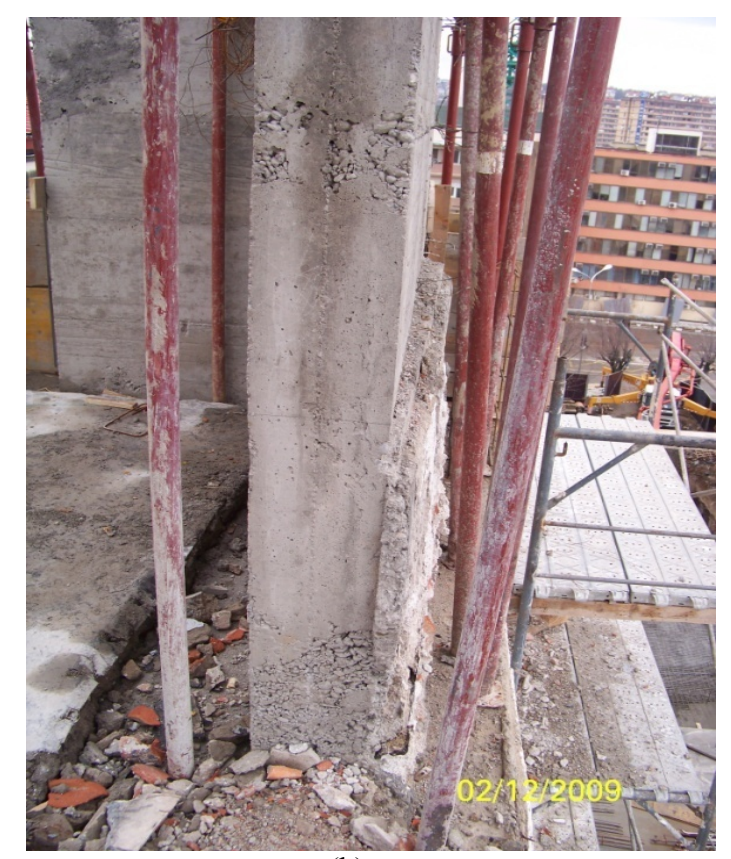

(b)

Fig. 9 (a) Shear wall and column jacketing tied together; (b) shear wall under construction, Block B-top floor.

Whilst the foundations of the blocks A and B were strengthened with reinforcement bars, the existing reinforced concrete columns were strengthened (Figs. $8 \mathrm{a}$ and $8 \mathrm{~b}$ ) with an original metal lattice confining structure as further shown in Figs. 7 and 8. New shear walls are connected with existing r. c. structure as shown in Fig. 9.

\section{Conclusions}

(1) What had initially been considered is the structural retrofitting with fibre reinforced polymers such as carbon fibres or $\mathrm{x}$ metal bracing. However, the authors are satisfied that the targeted compliances were achieved using conventional solutions such as jacketing, shear walls, etc. with a lower price-using 
local materials, skills and resources;

(2) The principal challenge of preserving an old landmark structure in the historic part of the city through retrofitting its structure and putting it in-line with the modern code requirements (Eurocodes) —has been successfully achieved and the client received the targeted product;

(3) The first author have personally achieved and gained professionally, whilst the reliability of the structure has been increased in cases of extreme natural hazards such are earthquakes under a very tight time schedule and constraints;

(4) Nowadays, the name of the hotel is no longer Illyria Hotel but it changed into Swiss Diamond Hotel [8], and it is certainly the best hotel in the City of Prishtina.

\section{References}

[1] EN 1997-1:2004/AC:2009, Eurocode 7: Geotechnical Design-Part 1: General Rules, Comité Européen de
Normalisation (CEN), Bruxelles, 2009.

[2] EN 1991-1-1:2002/AC 2009 Eurocode 1: Actions on Structures-Part 1-1: General Actions-Densities, Self-weight, Imposed Loads for Buildings, Comité Européen de Normalisation (CEN), Bruxelles, 2009.

[3] EN 1991-1-1:2003/AC 2009 Eurocode 1-Actions on Structures-Part 1-3 to 1-7, Comité Européen de Normalisation (CEN), Bruxelles, 2009.

[4] Eurocode 2: Design of Concrete Structures-Part 1-1: General Rules and Rules for Building, Comité Européen de Normalisation (CEN), Bruxelles, 2004.

[5] EN 1998-1:2004/AC:2009, Eurocode 8: Design of Structures for Earthquake Resistance-Part 1: General Rules, Seismic Actions and Rules for Buildings, Comité Européen de Normalisation (CEN), Bruxelles, 2009.

[6] GEOING—Geomechanical Report, Complex Illyria, Prishtinë, Hristo Georgijevski responsible engineer, Skopje, 2009.

[7] U. Smoltczyk, Geotechnical Engineering Handbook, Volume 3, Ernst \& Sohn, Berlin, 2003.

[8] Swiss Diamond Hotel Web Site, www.swissdiamondhotelprishtina.com (accessed Feb. 12, 2013). 